\title{
Exploration on the Application of WeChat Official Accounts Platform in the Teaching Reform of Analytical Chemistry in Medical Universities
}

\author{
Xianjiu Liao, Qichuan Huang, Yan Li, Suoyi Huang, Qianli Tang* \\ Youjiang Medical University for Nationalities, Baise, China \\ Email: *htmgx919@163.com
}

How to cite this paper: Liao, X. J., Huang, Q. C., Li, Y., Huang, S. Y., \& Tang, Q. L. (2020). Exploration on the Application of WeChat Official Accounts Platform in the Teaching Reform of Analytical Chemistry in Medical Universities. Creative Education, 11, 1462-1468.

https://doi.org/10.4236/ce.2020.118106

Received: August 3, 2020

Accepted: August 25, 2020

Published: August 28, 2020

Copyright $\odot 2020$ by author(s) and Scientific Research Publishing Inc. This work is licensed under the Creative Commons Attribution International License (CC BY 4.0).

http://creativecommons.org/licenses/by/4.0/

(c) (i) Open Access

\begin{abstract}
Objective: To construct a teaching mode based on WeChat Official Accounts Platform and to discuss its teaching effect in analytical chemistry courses in medical colleges and universities. Methods: The teaching mode based on WeChat Official Accounts Platform is used to teach the experimental subjects. After the course, the teaching effect is evaluated by questionnaire survey. Results: The experimental subjects are satisfied with the learning effect of the new teaching mode and have a good learning experience. Conclusion: The teaching mode and teaching form based on WeChat Official Accounts Platform are novel, which can improve students' interest in learning, increase their initiative in learning and advance their self-learning ability, and help to upgrade the teaching effect of analytical chemistry in medical universities.
\end{abstract}

\section{Keywords}

WeChat Official Accounts Platform, Medical universities, Analytical Chemistry, Teaching Reform

\section{Introduction}

As a new interdisciplinary subject developed in recent decades, analytical chemistry is a compulsory basic course for students of relevant specialties in medical colleges and universities such as medical laboratory technology, pharmacy and Chinese medicine. The course of analytical chemistry is basic and professional. Its purpose in medical colleges and universities is to enable students to master theoretical knowledge, firmly establish the concept of "quantity", cultivate students' practical operation skills, and form rigorous work style and scien- 
tific attitude of seeking truth from facts (Chen, Dang, \& Huang, 2017). As the content of analytical chemistry is abstract and difficult to understand, the class hours of basic courses in medical colleges and universities have been cut down, and the teaching content has progressed too fasts, students generally reflect that the course is of great difficulty, which leads to the lack of enthusiasm of students and the absence of extracurricular interaction between teachers and students. Therefore, how to improve the interest of medical college students in learning analytical chemistry and spur the teaching effect of analytical chemistry is extremely urgent (Xu, Li, Lyu, Liu, \& Li, 2020).

Following the rapid development of information technology, the popularization and use of smartphones, and the rapid intervention of network resources and technologies in teaching, teachers are no longer the mere source of knowledge for students. Teaching behavior relying on modern network communication technology is changing the traditional teaching methods (Chen \& Tian, 2019). WeChat, a software launched by Tencent in 2011, can quickly send voice, short messages, videos, animations, pictures and text. WeChat Official Accounts Platform can realize all-round communication and interaction with specific groups via pictures, text, voice, video, graphic messages and other content. Therefore, WeChat Official Accounts Platform is a concrete and easy-to-operate way to realize "Internet plus education" (Zhang, Xu, Niu, Ye, Wan, \& Su, 2020). We have built a teaching mode based on WeChat Official Accounts Platform, which is applied to the teaching of analytical chemistry for Chinese medicine specialty, in a bid to boost students' interest in learning and the teaching effect of analytical chemistry.

\section{Research Objects and Methods}

\subsection{Research Objects}

The 2018 Chinese Medicine Specialty Class of Youjiang Medical University for Nationalities is selected as the experimental subject, with a total of 45 students. The course of analytical chemistry is scheduled in the second semester of the first grade and includes 54 hours, of which 36 hours are theoretical and 18 hours are practical. The 3rd edition Analytical Chemistry textbook edited by Qiu Ximin of China Medical Science and Technology Publishing House is adopted.

\subsection{Research Methods}

The teacher establishes the WeChat Official Account teaching platform and informs the students to follow the WeChat Official Account by scanning the code. Registration shall be made according to the real name and student number, and the relevant instructions for the use of the student learning platform shall be sent to the student. The requirements for teachers at each class are as follows: 1) Preview before class: Teachers will release the key points, difficulties and relevant materials of this class to WeChat Learning Platform before class, and students will learn independently based on relevant requirements. 2) Classroom teaching: 
Students sign in on WeChat Learning Platform; Teachers can use various learning assistance apps in WeChat, such as Moso Tech and Questionnaire star, to conduct classroom Q\&A, online tests and group discussions to strengthen interaction and communication with students. 3) After-class review: After class, teachers can post test questions through WeChat platform to review students' learning effect, during which, students finish the test within the specified time, and teachers score on WeChat Learning Platform. 4) "You can learn everywhere and always learn": at ordinary times, teachers and students have interactive communication and learning anytime and anywhere via WeChat Learning Platform to solve problems in learning in time. Teachers can answer and analyze students' learning according to their discussions. In return, students can also give feedback on teaching anytime and anywhere to help teachers improve teaching methods and optimize teaching programs in time.

\subsection{Effectiveness Evaluation}

After the term examination, 30 students were randomly selected to conduct a questionnaire survey, so that students could evaluate their satisfaction and learning effect with the teaching mode based on WeChat Official Accounts Platform. The evaluation contents of the questionnaire include: 7 aspects including overall evaluation, practical operation ability, critical thinking ability, self-learning ability, improvement of the information literacy, improve learning interest and increase learning initiative (see Table 1 ), as well as the satisfaction evaluation of students on the learning platform (see Table 2).

Table 1. Learner's teaching effect score (\%).

\begin{tabular}{cccc}
\hline Survey items & Very satisfied & Satisfied & Satisfaction rate \\
\hline Overall evaluation & 16.67 & 76.67 & 93.33 \\
Practical operation capability & 20.00 & 66.67 & 86.67 \\
Critical thinking ability & 20.00 & 66.67 & 86.67 \\
Self-learning ability & 13.33 & 73.33 & 86.67 \\
Improve the information literacy & 6.67 & 80.00 & 86.67 \\
Improve learning interest & 13.33 & 76.67 & 90.00 \\
Increase learning initiative & 16.67 & 70.00 & 86.67 \\
Total average score & 15.24 & 72.86 & 88.10
\end{tabular}

Table 2. Learners' satisfaction score on WeChat learning platform (\%).

\begin{tabular}{lccc}
\hline \multicolumn{1}{c}{ Survey items } & Very agreed & Agreed & Consent rate \\
\hline $\begin{array}{l}\text { WeChat platform is helpful for accessing to the required } \\
\text { learning materials }\end{array}$ & 20.00 & 70.00 & 90.00 \\
$\begin{array}{l}\text { WeChat platform is helpful for using fragmented time to } \\
\text { learn }\end{array}$ & 16.67 & 70.00 & 86.67 \\
$\begin{array}{l}\text { Learning platforms make the teaching quality evaluation } \\
\text { system more complete }\end{array}$ & 23.33 & 66.67 & 90.00 \\
\hline
\end{tabular}




\section{Continued}

\begin{tabular}{lccc}
\hline $\begin{array}{l}\text { Learning platforms can better track and grasp the } \\
\text { learning effect }\end{array}$ & 23.33 & 63.33 & 86.67 \\
$\begin{array}{l}\text { Learning platforms help consolidate learning content } \\
\begin{array}{l}\text { WeChat Platform promotes timely communication } \\
\text { between teachers and students }\end{array}\end{array}$ & 20.00 & 63.33 & 83.33 \\
\begin{tabular}{l} 
Total average score \\
\hline
\end{tabular} & 21.11 & 70.00 & 93.33 \\
\hline
\end{tabular}

\subsection{Statistical Results}

The data was processed and analyzed by SPSS 22.0 software. The enumeration data was expressed as $\mathrm{n}(\%)$ and the measurement data as $(\bar{x} \pm s)$.

\section{Results}

\subsection{Investigation on the Teaching Effect of Learners}

Catering to the development trend of "Internet plus Education", teachers should innovate the teaching mode of information technology courses, cultivate students' learning ability under the information environment and good habits of using information technology to learn, and encourage students to use information means to learn actively, independently and cooperatively (Liu, 2020). The results of the survey on the teaching effect of learners are shown in Table 1. The overall satisfaction rate of students reaches $93.33 \%$ for the teaching mode based on WeChat Official Accounts Platform. Among them, the scoring interval based on the Duifene Teaching Platform is mainly concentrated in the satisfied interval, accounting for $72.86 \%$; the second is very satisfied, accounting for $15.24 \%$; since there are few students who are not satisfied or very satisfied or the proportion is extremely low, the remaining scoring intervals basically fall into the general intervals.

\subsection{A Survey of Learners' Satisfaction with WeChat Learning Platform}

After the course, a questionnaire survey was conducted on the satisfaction of experimental students with WeChat Learning Platform. The results reveal that (see Table 2), the scoring interval for WeChat Learning Platform falls mainly into the satisfaction interval, accounting for $67.22 \%$. The second is very satisfied, accounting for $21.11 \%$; the total average satisfaction rate is $88 \%$. Since there are few students who are not satisfied or very satisfied or the proportion is extremely low, the remaining scoring intervals basically fall into the general intervals.

\subsection{Learners' Final Achievements}

As most of our college students come from remote areas in western China, their entrance results are poor, and their chemical foundation is also weak. Some students haven't studied chemistry according to the college entrance examination subjects, so the overall chemical foundation is very undesirable. However, after 
one semester's efforts, their final comprehensive score was $(70.42 \pm 8.22)$ and the passing rate was $93.18 \%$. The examination results have improved with great progress and the students were satisfied with their examination performance and teaching results.

\section{Discussion}

Traditional medical education adopts a teaching mode in which teachers speak and students listen. It is difficult for teachers to grasp whether students preview the lesson, whether they can master the knowledge of the courses to be taught in class, and whether they consolidate and strengthen the knowledge after class, and it is also hard for teachers to get feedback from students in time (Wu, Lan, Huang, Wei, Cao, \& Wei, 2020). The teaching mode based on WeChat Official Accounts Platform can get students' information feedback in time, which is conducive to the extension of classroom teaching, teachers' track and grasp of students' learning conditions, and promotes a win-win situation in teaching and learning.

1) It is conducive to the extension of classroom teaching.

It is difficult to grasp students' knowledge in real time in traditional classroom teaching. Based on the teaching mode of WeChat Official Accounts Platform, students can learn independently anytime and anywhere by provision of preview and review materials using such platform before and after class. Also, teachers can guide students and answer questions in time. $90 \%$ of the experimental students hold WeChat platform is helpful to obtain the required learning materials, $87 \%$ of the experimental students think WeChat platform is helpful for using fragmented time to learn, and $83 \%$ of the experimental students argue WeChat Learning Platform helps to consolidate learning content, which indicates that WeChat Official Accounts Platform can fully mobilize the enthusiasm of students to "learn anywhere and anytime" and is conducive to the extension of classroom teaching.

2) It is helpful to track and master students' learning conditions.

WeChat Official Accounts Platform makes interactive communication convenient and fast. Students can post knowledge points they do not understand on WeChat Official Accounts Platform anytime and anywhere for everyone to communicate and discuss. Teachers can track and master students' learning conditions through WeChat Official Accounts Platform. When many students do not understand a certain knowledge point, teachers can explain it in detail in class and adjust the teaching design in time and flexibly. $87 \%$ of the experimental students deem WeChat Learning Platform can better track and master the learning effect, 93\% believe WeChat platform promotes timely communication between teachers and students, and 90\% think WeChat Learning Platform makes the teaching quality evaluation system more perfect. This discloses that WeChat Official Accounts Platform can track and master students' learning information in a more timely manner, which is convenient for teachers to optimize teaching 
design and thus improve teaching effect.

3) It promotes a win-win situation in teaching.

Under the teaching mode based on WeChat Official Accounts Platform, the students have gained a lot. $87 \%$ of the experimental students consider that the new teaching mode has improved their practical operation ability, critical thinking ability and self-learning ability. $90 \%$ of the experimental students think that the new teaching mode has increased their interest in learning and $87 \%$ argue that the new teaching mode has spurred their initiative in learning, which shows that this teaching mode has enhanced their dominant position and mobilized their interest and enthusiasm in learning. Teachers have also benefited greatly from it. Under the concept of "student-centered", teachers' authority has been challenged (Ni, Li, \& Huang, 2019). Teachers are required to update their teaching concepts, reshape their roles, improve their information literacy, enhance their information teaching ability, and innovate their education and teaching modes so as to follow the development trend of "Internet plus Education".

\section{Conclusion}

At present, the pace of informatization is accelerating rapidly, and the impact of information technology on education is becoming increasingly obvious. In the era of "Internet plus Education", we should promote the integration of information technology and curriculum education, update teaching concepts, reform the existing classroom teaching mode, and provide students with rich and colorful educational environment and learning tools. Therefore, it is the general trend to implement curriculum teaching reform leveraging WeChat Official Accounts Platform. Of course, everything has two sides; the use of the Fenyi platform allows students to use mobile phones in class, so teachers need to strengthen monitoring. The analytical chemistry teaching mode based on WeChat Official Accounts Platform not only strengthens the interaction between teachers and students, but also is beneficial to the upgrading of teachers' teaching concepts. This teaching mode conforms to the development tendency of "Internet plus Education", changes the traditional teaching mode, improves the dominant position of students, mobilizes students' interest and enthusiasm in learning, enables students to learn anytime and anywhere, drives the in-depth integration of new technologies and education and teaching, advances the stable development of education and teaching, and is worth promoting.

\section{Fund Program}

The 2017 Guangxi Vocational Education Teaching Reform Research Project + "Research and Practice of Flip Classroom Based on WeChat Platform Combined with Formative Evaluation in Teaching-Taking Higher Vocational Analysis and Testing Related Courses as an Example" + (GXGZJG2017A057).

\section{Conflicts of Interest}

The authors declare no conflicts of interest regarding the publication of this paper. 


\section{References}

Chen, H., Dang, X., \& Huang, J. (2017). "Internet plus Education” Helps to Build Analytical Chemistry Curriculum Group. University Chemistry, 32, 12-16.

Chen, J., \& Tian, Q. (2019). Transformation of Teachers' Classroom Role and Its Implementation Path under the Environment of "Internet plus Education". Journal of Educational Development, No. 12, 79-84.

Liu, Z. (2020). Research on College English Teaching Reform and Development in the Context of Internet plus Times. Overseas English, No. 2, 169-170.

Ni, A., Li, G., \& Huang, X. (2019). Application of Grouping Micro-Video Competition Mode in Large Class Biochemistry Teaching. Journal of Youjiang Medical University for Nationalities, 41, 222-224.

Wu, P., Lan, Z., Huang, W., Wei, L., Cao, C., \& Wei, H. (2020). Application of Mixed Teaching Mode based on MOOC in Medical Undergraduate Interns. Journal of Youjiang Medical University for Nationalities, 42, 119-122.

Xu, K., Li, N., Lyu, Z., Liu, W., \& Li, D. (2020). Exploration on the Cultivation of Middle School Students' Logical Thinking in Analytical Chemistry. Education Modernization, 7, 85-89.

Zhang, M., Xu, H, Niu, B., Ye, S., Wan, D., \& Su, Y. (2020). Application of Flipped Classroom Based on WeChat Platform in Clinical Practice Teaching in Emergency Department. Modern Medicine \& Health, 36, 1928-1931. 